\title{
Endovascular treatment of blister aneurysms
}

\author{
Geoffrey W. Peitz, MD, Christopher A. Sy, MD, and Ramesh Grandhi, MD \\ Department of Neurosurgery, University of Texas Health San Antonio, Texas
}

\begin{abstract}
Blister aneurysms are rare cerebrovascular lesions for which the treatment methods are reviewed here, with a focus on endovascular options. The reported pathogenesis of blister aneurysms varies, and hemodynamic stress, arterial dissection, and arteriosclerotic ulceration have all been described. There is consensus on the excessive fragility of blister aneurysms and their parent vessels, which makes clipping technically difficult. Open surgical treatment is associated with high rates of complications, morbidity, and mortality; endovascular treatment is a promising alternative. Among endovascular treatment options, deconstructive treatment has been associated with higher morbidity compared with reconstructive methods such as direct embolization, stent- or balloon-assisted direct embolization, stent monotherapy, and flow diversion. Flow diversion has been associated with higher technical success rates and similar clinical outcomes compared with non-flow diverting treatment methods. However, delayed aneurysm occlusion and the need for antiplatelet therapy are potential drawbacks to flow diversion that must be considered when choosing among treatment methods for blister aneurysms.
\end{abstract}

https://thejns.org/doi/abs/10.3171/2017.3.FOCUS1751

KEY WORDS blister aneurysm; endovascular; comparison; flow diverter

$\mathrm{I}$ NTRACRANIAL blister aneurysms are a rare but surgically challenging vascular pathology for which the ideal treatment is unclear. In 1979 Ohara and colleagues described a series of aneurysms arising from nonbranching sites of sclerotic parent arteries, accounting for $1 \%$ of the aneurysms encountered in their practice. ${ }^{42}$ Due to the fragility of the sclerotic parent vessels, the authors recommended that "a completely different surgical management must be taken from that used in cases of [classic] berry aneurysms." Whereas some aneurysms at sclerotic nonbranching sites may have the berry shape, others have a half-dome shape in which the neck is wider than the dome. In 1988, Takahashi used the Japanese word "chimame," meaning "blood blister," to describe aneurysms with such a shape.$^{53}$ Blister aneurysms have been reported in the anterior and posterior circulation, but the most common location is the supraclinoid internal carotid artery (ICA)..$^{34,42}$ Blister aneurysms of the ICA have a reported proportion of $0.3 \%-1.7 \%$ among cerebral aneurysms treated operatively, and up to $6.6 \%$ among ruptured cerebral aneurysms. ${ }^{1,37,38,40}$

It is important to note that although Ohara and colleagues' original paper described aneurysms arising from multiple cerebral arteries, ${ }^{42}$ the term blister aneurysm is often restricted to half-dome-shaped aneurysms from nonbranching sites of the dorsal ICA only. 1,18,24,35,38,40,53 Other authors use the term to describe such aneurysms of both the ICA and basilar artery, 3,7,36,48,52 and some authors include such aneurysms of the middle cerebral artery (MCA), anterior cerebral artery (ACA), vertebral artery (VA), posterior cerebral artery (PCA), and posterior inferior cerebellar artery (PICA) ${ }^{4,15,31,35,45,46,49}$ Whether blister aneurysms of the dorsal ICA have the same or different pathogenesis and natural history as similarly shaped aneurysms of nonbranching sites of other cerebral arteries has not been proven.

Perhaps due to the rarity of blister aneurysms, the described pathogenesis is not conclusive. Histological examination of blister aneurysms usually reveals a gap in the arterial wall covered by thin, fibrinous tissue, suggesting that the entity is, in fact, a type of pseudoaneurysm (Figs. 1 and 2). Furthermore, authors have angiographically demonstrated increase in size and change in shape from the blister shape to the classic berry shape in the first several days after presentation, suggesting a dynamic pathol-

ABBREVIATIONS ACA = anterior cerebral artery; FDs = flow-diverting devices; ICA = internal carotid artery; MCA = middle cerebral artery; $m R S=$ modified Rankin Scale; $\mathrm{PCA}=$ posterior cerebral artery; PED, PED-Shield = Pipeline embolization device, $\mathrm{PED}$ with Shield technology; PICA = posterior inferior cerebellar artery; SAH = subarachnoid hemorrhage; $V A=$ vertebral artery. 

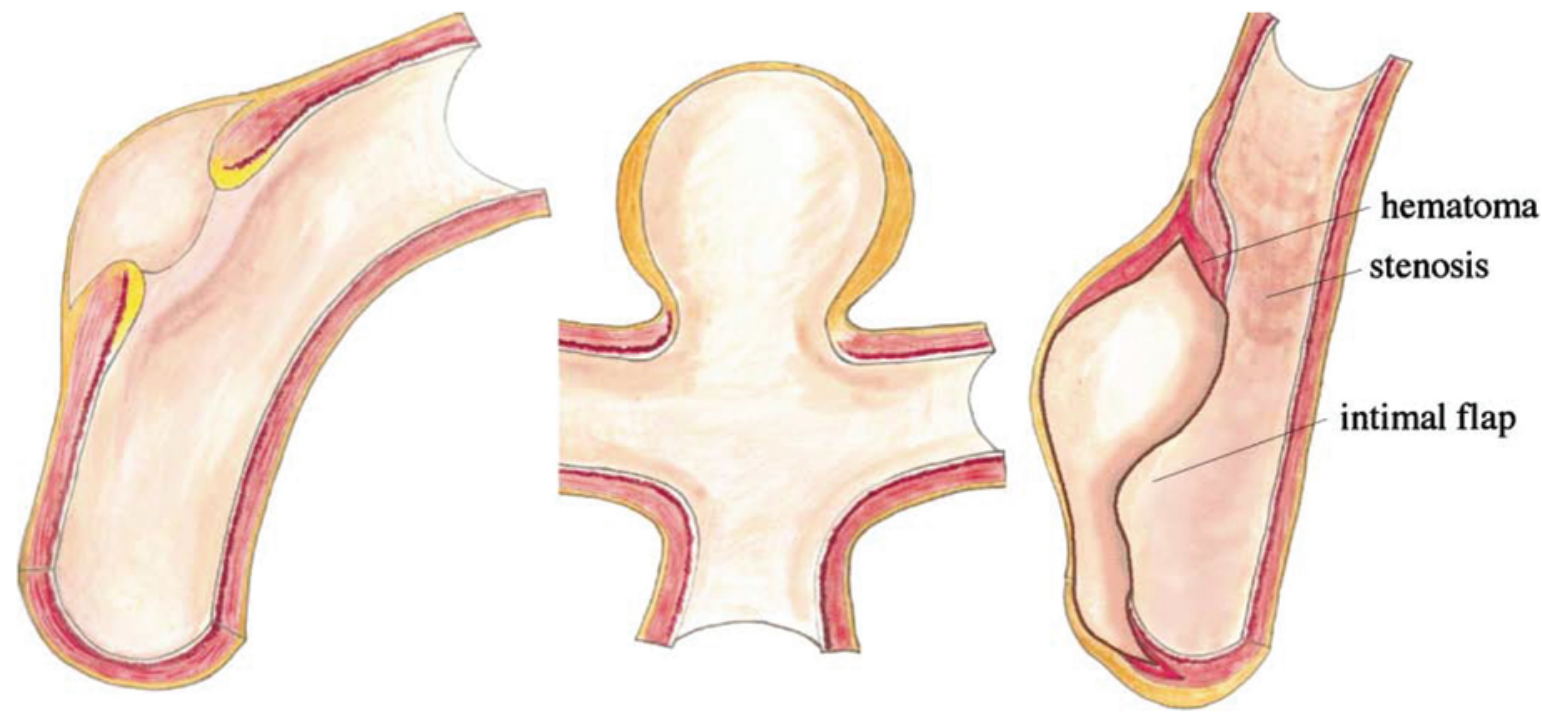

FIG. 1. Illustrations demonstrating structural differences among 3 types of aneurysms. The BBA (blood blister-like aneurysm) (left) is a focal wall defect covered with thin fibrous tissue located where the vessel displays the most curvature, generally associated with atherosclerosis. The wall of a berry aneurysm (center) is composed of a thickened intima and adventitia. In a dissecting aneurysm (right), the wall is dissected for a certain distance, and both stenotic and dilated portions can be observed. Reproduced with permission from AANS/JNSPG Publications. Abe M, Tabuchi K, Yokoyama H, Uchino A: Blood blisterlike aneurysms of the internal carotid artery. J Neurosurg 89:419-424, 1998.

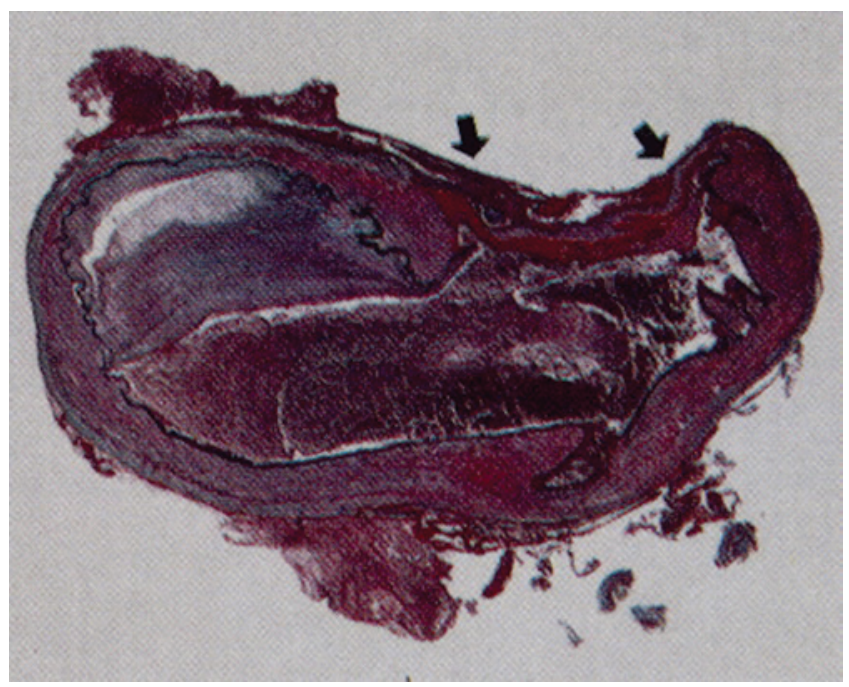

FIG. 2. Cross-section of the internal carotid artery adjacent to the rupture point (Elastica-Masson stain). The internal elastic lamina and media have disappeared at the border between the eccentrically sclerotic and normal carotid wall (arrows). The gap in the internal elastica (between the 2 arrows) was covered with normal adventitia and fibrinous tissue. This portion was not composed of collagenous tissue ordinarily seen in an aneurysmal wall. Neither infiltration of inflammatory cells nor dissection of the artery was observed. Reproduced with permission from Tatsuya Ishikawa et al: Pathological consideration of a "blister-like" aneurysm at the superior wall of the internal carotid artery: Case report. Neurosurgery (1997) 40(2):403-406, by permission of Oxford University Press. Published by Oxford University Press online at: https://academic. oup.com/neurosurgery/article/40/2/403/2734083/Pathological-Consideration-of-a-Blister-like?searchresult=1. Published under a Standard License only. ogy. 1,34,40,54 Although angiographic and intraoperative observational studies have associated blister aneurysms with ICA dissection, ${ }^{18,28,37,40,51}$ authors who have histologically examined blister aneurysms have reported no evidence of dissection, further confounding our understanding of the pathogenesis of this entity. ${ }^{1,23}$

Arteriosclerosis and subsequent ulceration have also been posited as key factors leading to the development of blister aneurysms, ${ }^{1,23,42}$ but Ogawa and colleagues suggested in 2000 that development of these aneurysms is more strongly associated with hypertension than arteriosclerosis. ${ }^{40}$ Of note, several studies have documented blister aneurysm locations at points of abrupt curvature of the ICA, thus supporting the importance of hemodynamic stress in contributing to the pathogenesis. ${ }^{1,38,40}$ There is at least 1 case report of a blister aneurysm forming due to infectious vasculitis of the ICA wall with Aspergillus, adding yet another etiology to consider in the pathophysiology of this aneurysm subtype. ${ }^{41}$ Despite these significantly varied explanations behind the mechanisms leading to blister aneurysm formation, investigators have consistently described fragility of the blister aneurysm as well as adjacent parent vessel walls, a high tendency to rupture, and unique clinical challenges in terms of both diagnosis and treatment.

The fragility of blister aneurysms makes their treatment technically challenging. Clipping alone is sometimes feasible, but frequent rupture or vessel tearing necessitates alternative primary or secondary techniques. Early papers advocated wrapping with muscle, with subsequent adhesive coating or clipping. ${ }^{38,42}$ Later, authors described use of the Sundt encircling clip, clip-wrapping with synthetic wrapping material (Fig. 3), and in some cases, ICA trap-

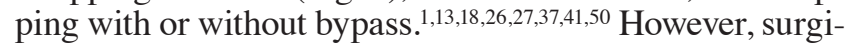




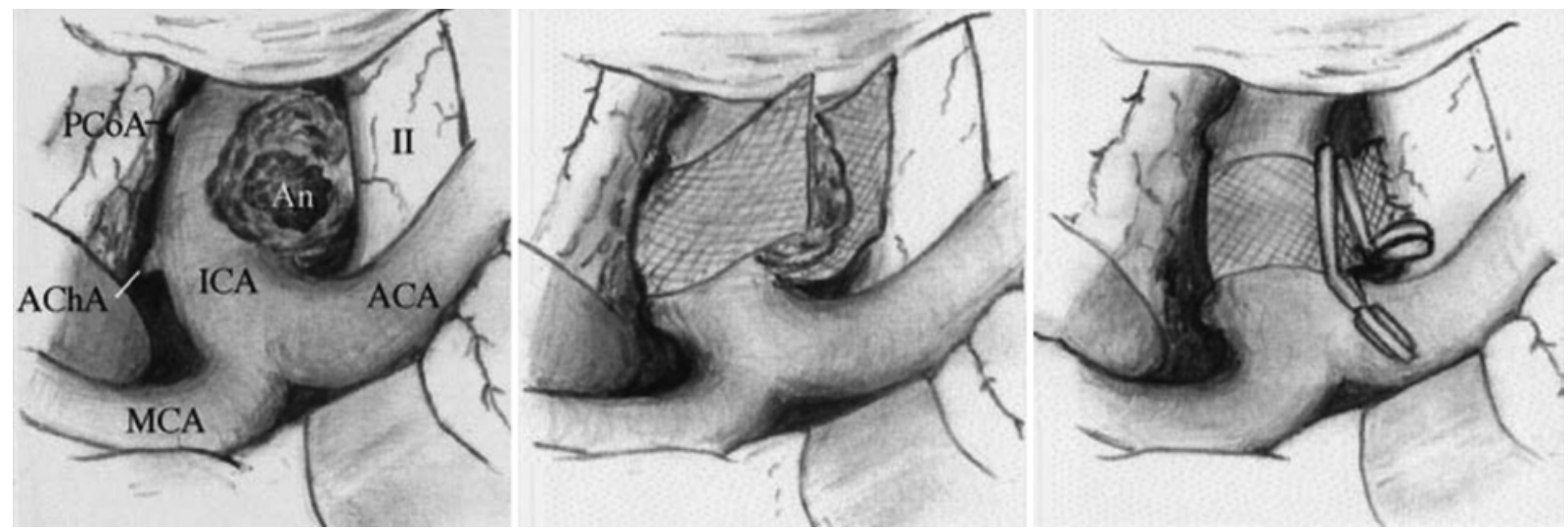

FIG. 3. Drawing of surgical findings showing a BBA on the anteromedial wall of the left ICA (left) and drawings of the operative procedure showing wrapping with a strip of gauze (center) and clipping with 2 clips (right). AChA = anterior choroidal artery; $A n=$ aneurysm; II = optic nerve; $\mathrm{PCOA}=$ posterior communicating artery. Reproduced with permission from AANS/JNSPG Publications. Abe M, Tabuchi K, Yokoyama H, Uchino A: Blood blisterlike aneurysms of the internal carotid artery. J Neurosurg 89:419-424, 1998.

cal treatment has been shown to have a high rate of complications, morbidity, and mortality. ${ }^{18,37,41}$ Endovascular treatment represents a promising alternative, with limited retrospective evidence showing lower morbidity and mortality involving endovascular techniques compared with open surgical treatment. ${ }^{18,44,45}$

Given these results, the approach to treatment of blister aneurysms in recent times has shifted from open surgical treatment to endovascular treatment. This is especially the case with ongoing innovations in regard to endovascular techniques and devices. ${ }^{43,47}$ As in the case of open surgical approaches for blister aneurysm treatment, endovascular approaches may involve either deconstructive or reconstructive techniques. Parent vessel deconstruction with endovascular coil or balloon occlusion is definitive and technically straightforward to perform but is not feasible in many contexts, due to inadequacy of collateral circulation and potential for stroke..$^{14}$ Although this technique has a high rate of initial occlusion compared with other endovascular therapies, it is associated with a significantly higher rate of perioperative stroke compared with endovascular reconstructive treatment. ${ }^{48}$ Endovascular reconstructive options include direct embolization with or without balloon or stent assistance, single or overlapping stents alone, and flow diversion. Fortunately, all of these endovascular options have demonstrated success. We will discuss the unique technical hurdles, clinical nuances, and patient outcomes that have been reported in the literature.

\section{Direct Embolization}

As noted by Fiorella and colleagues in 2006, direct embolization is only possible in cases in which a saccular component of the lesion is present, which oftentimes is either nonexistent or too small. ${ }^{14}$ Moreover, the physical characteristics of blister aneurysms that make open surgical treatment challenging also make occlusion with coils or a liquid embolic agent challenging. The thin, fragile domes that render these lesions more prone to intraoperative rupture make the technical aspect of coil introduction particularly risky. Also, the characteristic wide neck of blister aneurysms makes the initial placement and retention of occlusion material difficult, while also increasing the risk that any applied material can dislodge and occlude vessels unintentionally. ${ }^{2}$ Thus, reported cases involving direct embolization of blister aneurysms from most centers were performed with the assistance of a balloon or stent (Fig. 4), and primary coiling without any assistance is rare. ${ }^{12,15,18,22,36,46,52}$ The use of a liquid embolic agent for treatment is exceedingly rare and has not been reported without the use of concomitant stenting.

Rates and definitions of success vary, but 1 study of 43 patients with blister aneurysms reported an initial complete occlusion rate of $60.4 \%$, with $90.7 \%$ of patients treated using stent-assisted coiling. ${ }^{15}$ Another study reported successful occlusion with stent-assisted coiling in 5 of 8 patients in their series. ${ }^{12}$ Between the 2 aforementioned studies and 2 separate studies including patients with ruptured blister aneurysms who underwent treatment predominantly with stent-assisted coil embolization, good clinical outcomes were reported, with modified Rankin Scale (mRS) scores of $\leq 2$ in the vast majority of patients. ${ }^{12,15,22,36}$ Despite the potential for good angiographic and clinical outcomes, actual use of stent-assisted embolization is limited based on technical factors, because many blister aneurysms have domes that are too small or too morphologically challenging to accommodate embolic material. Nonetheless, direct embolization techniques represent a conceivable endovascular option that offers immediate occlusion and, in the context of patients presenting with subarachnoid hemorrhage (SAH), the ability to secure the aneurysm with concomitant reduction in the potential for rerupture.

\section{Stenting Alone}

Among the reconstructive options for blister aneurysms discussed herein, the use of stents alone is the least common. In most reports of stent use, it has been in conjunction with either coiling or liquid embolization, as noted in 

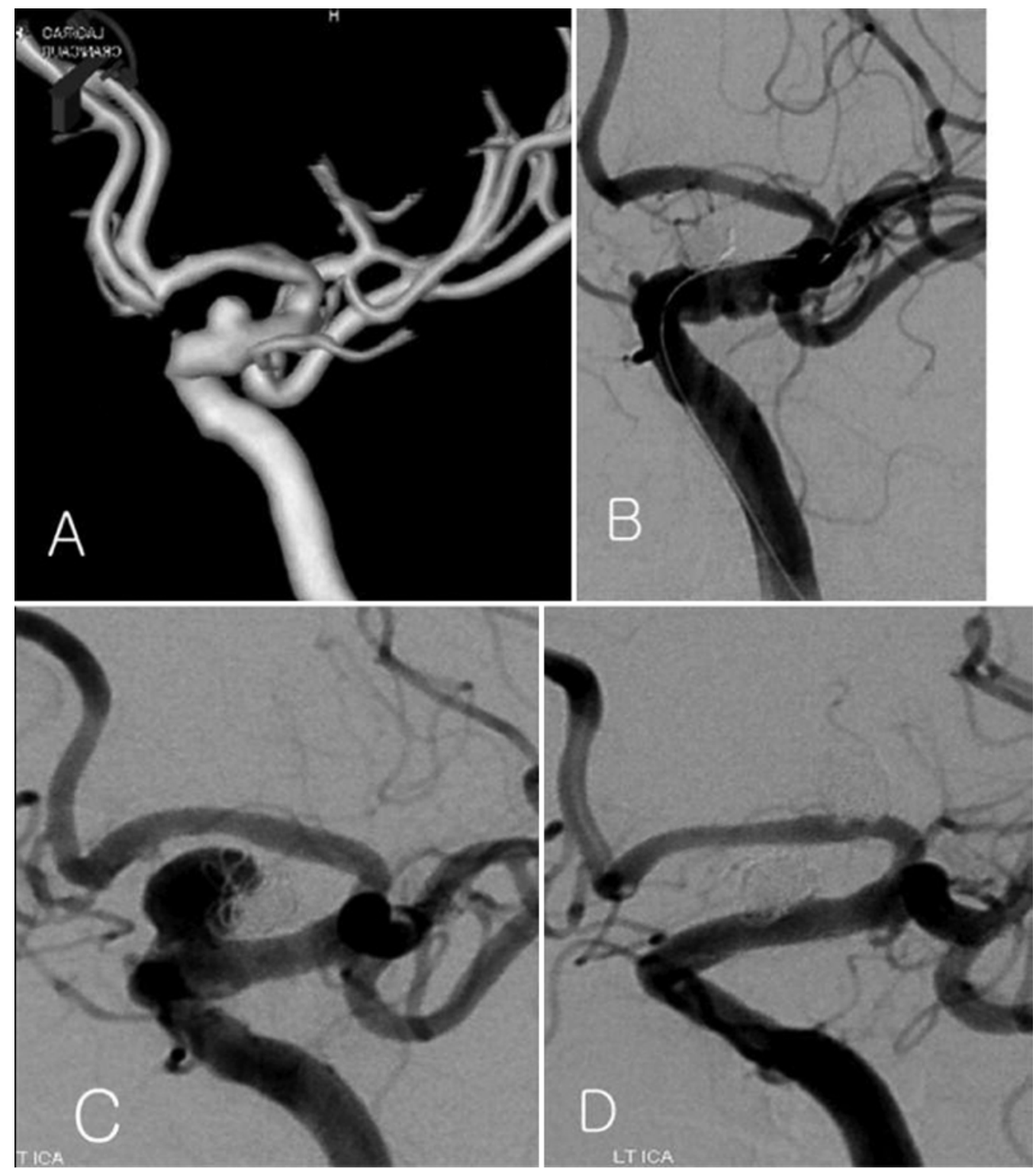

FIG. 4. Case 3. Three-dimensional reconstruction angiogram (A) showing the typical appearance of a BBA at the left ICA. After SAC (stent-assisted coil) embolization, a postembolization control angiogram (B) shows complete occlusion of the BBA. The 2 months' follow-up angiogram (C) reveals regrowth of the BBA. Immediately after retreatment with a covered stent, the control angiogram (not shown) revealed subtle contrast media leakage into the recurred sac. The 1-week follow-up angiogram (not shown) revealed minimal neck remnant, and the 3-month follow-up angiogram (D) demonstrates complete occlusion of the BBA with reconstruction of the ICA. Reproduced with permission from AANS/JNSPG Publications. Lee B-H, Kim BM, Park MS, Park S II, Chung EC, Suh SH, et al: Reconstructive endovascular treatment of ruptured blood blister-like aneurysms of the internal carotid artery. J Neurosurg 110:431-436, 2009.

the previous section. Although previous authors described the application of endovascular stent reconstruction as monotherapy for treatment of intracranial aneurysms, to our knowledge Fiorella et al. in 2006 were the first to report the use of stent reconstruction alone in patients with blister aneurysms when they used the Neuroform (Stryker Neurovascular) stent in 2 patients with blister aneurysms of the right ICA treated with stenting alone. ${ }^{14}$ Neither patient experienced a neurological complication, with follow-up angiography demonstrating complete aneurysm occlusion at 4 months in one patient and near-complete aneurysm occlusion at 9 months in the other. In 2010, Gaughen and colleagues reported on 6 patients treated with a stent-instent technique using self-expanding Enterprise (Codman Neurovascular) or Neuroform stents. Immediate complete occlusion was documented in 3 patients, and retreatment with coil placement was needed for the remaining ones. ${ }^{16}$ In 2014, Walsh et al. reviewed 8 patients with blister aneurysms treated using endovascular stenting as monotherapy at their center. In all patients, multiple Enterprise and/ 

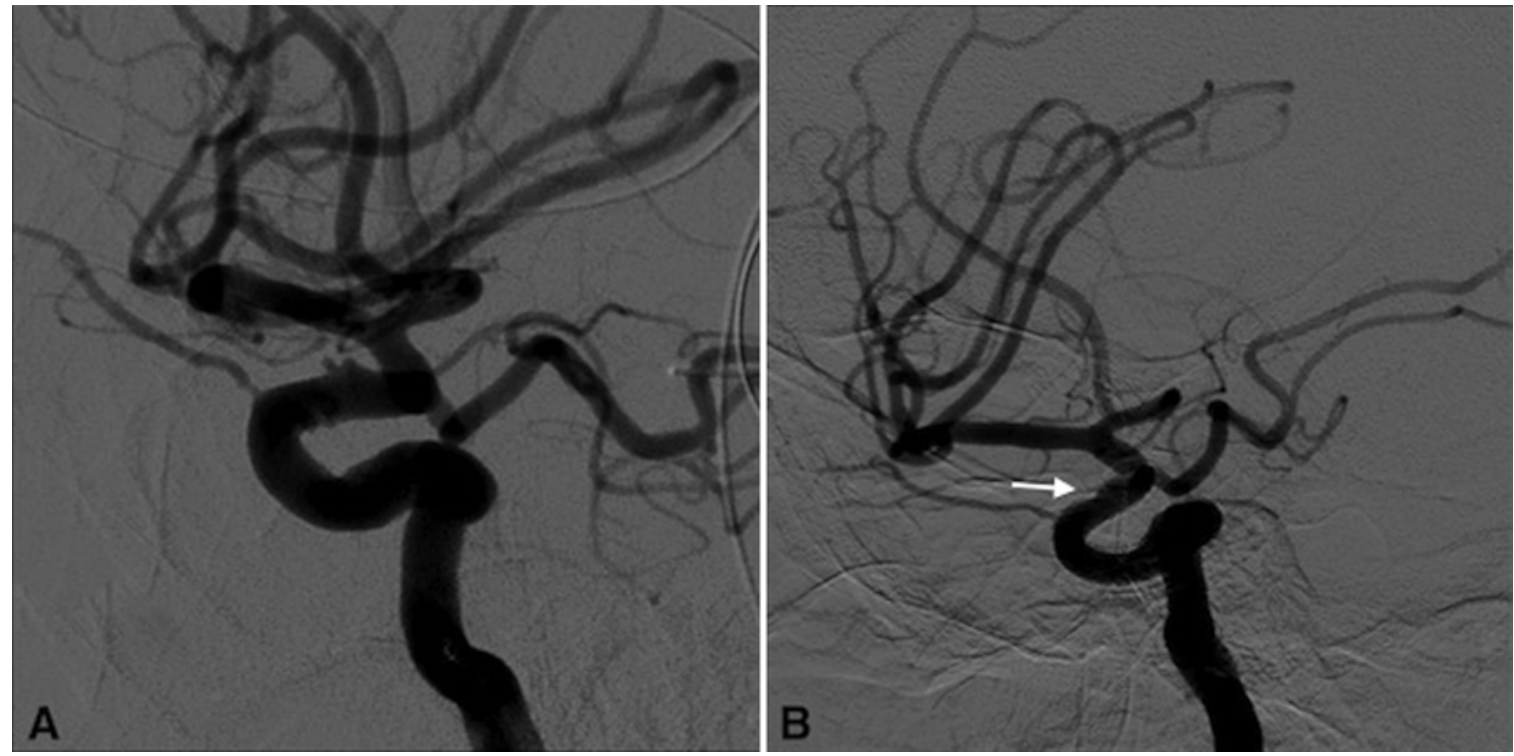

FIG. 5. Digital subtraction angiography showing blister aneurysms of the supraclinoid ICA in a patient presenting with SAH (A). At follow-up 6 months after placement of a PED, digital subtraction angiography showed occlusion of the blister aneurysms and remodeling of the parent vessel (B). Arrow indicates site of occluded blister aneurysm.

or Neuroform stents were used. Complete aneurysm occlusion was documented in 2 patients immediately after stent placement and in 3 more patients on follow-up angiograms. Of the remaining 3 patients, 2 had no residual filling on 1-year follow-up MR angiography, and 1 had rapid aneurysm expansion that required parent artery occlusion and bypass. ${ }^{55}$ Two more case series have reported blister aneurysm treatment with the use of a single Neuroform stent. Each reported 5 patients, all with long-term complete occlusion and no adverse complications. ${ }^{4,19}$

It is important to note that complete aneurysm thrombosis was demonstrated in some patients within a few days of intervention, but it was not demonstrated in others until long-term follow-up, which was, on average, 13.6 months in 1 report. ${ }^{4}$ Also, a few centers have reported success in achieving complete occlusion with good clinical outcomes by using covered stents specially designed for intracranial use, such as the WILLIS covered stent (MicroPort NeuroTech). ${ }^{11,29}$ Use of covered stents can achieve immediate occlusion, and may be a viable option that decreases the risk of early rerupture in these patients. Although not commonly used, stents (both covered and otherwise) are worth consideration in the setting of blister aneurysms that are not amenable to direct embolization and in which flow diversion is contraindicated or unavailable.

\section{Flow Diversion}

The use of flow-diverting devices (FDs) such as the Pipeline embolization device (PED; Medtronic Neurovascular) (Fig. 5) and Silk (Balt Extrusion) for treatment of blister aneurysms is gaining in popularity and has the potential for becoming the standard of care. $3,5,6,9,10,25,30-33,39,49$ In their 2017 study of 10 patients with ruptured blister pathology and an average Hunt and Hess score of 1.6 on presentation, Linfante et al. noted successful deployment of the PED in 9 patients. ${ }^{31}$ Eight of the 9 patients treated with the PED had a 90-day mRS score of 0 , and the remaining patient had a score of 1 . In 2014, Chalouhi and colleagues reported complete aneurysm occlusion and an $\mathrm{mRS}$ score of $\leq 2$ in all 8 patients in their series on PED treatment of blister aneurysms. ${ }^{7}$ Other smaller case series of the PED for blister pathology have reported complete occlusion of the blister aneurysm and an mRS score of $\leq$ 2 in all patients. ${ }^{10,21}$ Similar results with the SILK device were reported by Aydin and colleagues in 2015, in a retrospective study of 11 patients with ruptured blister aneurysms. Complete occlusion in all patients was achieved at the 6-month follow-up visit, and all had mRS scores of $\leq$ $2 .^{3}$

As encouraging as the use of FDs may seem in regard to treatment of blister aneurysms, it is important to note that their use is not completely benign. In 2014, Yoon et al. reported an mRS score of $\leq 2$ in 10 of their 11 patients, but there were 3 major complications, including an intraparenchymal hemorrhage resulting in death, an MCA infarction, and monocular blindness, as well as 2 asymptomatic complications including ICA dissection and ICA occlusion from stent thrombosis. ${ }^{56}$ As for the Silk device, a group in Turkey reported an $87.9 \%$ overall complete occlusion rate in a series of 32 patients. ${ }^{5}$ Two complications were reported in that series, with 1 thromboembolic event and 1 death due to postprocedural intraparenchymal hemorrhage. Furthermore, even when properly placed, FDs do not necessarily provide immediate aneurysm occlusion; there are reports of delayed rerupture of blister aneurysms after treatment with single FDs, sometimes resulting in death..$^{33,39}$

It is also of interest that systematic reviews have shown treatment of blister aneurysms with FDs to result in a higher rate of thromboembolic events compared with non-FD-mediated endovascular treatment, but there was no significant difference in the rate of rebleeding. ${ }^{44,48}$ Fur- 
thermore, although use of FD technology was found to provide a statistically significantly higher rate of mid- to long-term occlusion and a lower rate of retreatment, the difference in the rate of good neurological outcome was not statistically significant between groups. ${ }^{48}$

Finally, treatment of patients with ruptured blister aneurysms by using FDs poses a dilemma in patients who experience vasospasm. In 2013, McTaggart and colleagues described a patient who experienced delayed retraction of a PED used to treat a dissecting aneurysm of the PICA in the setting of vasospasm; the authors also experienced difficulty placing a second telescoping PED due to vessel constriction from spasm..$^{35}$ Indeed, the use of flow-diversion technology allows for preservation of endovascular access for treatment of vasospasm, which represents a key advantage of this reconstructive technique over other deconstructive treatment options. ${ }^{36,48}$ However, given that the aneurysm dome is not immediately secured with FD placement, ${ }^{48}$ appropriate blood pressure management in the acute setting is an important question. Thus, the risks associated with hyperdynamic therapy in patients experiencing vasospasm whose aneurysms were treated by FDs has not been documented in the literature.

\section{The Next Frontier of Flow-Diversion Technology}

Looking forward, technological advancement in FDs may decrease their thrombogenicity, obviating the need for dual antiplatelet therapy. The Pipeline embolization device with Shield (PED-Shield, Medtronic Neurovascular) technology mimics the thromboresistant outer leaflet of erythrocyte membranes and consists of a 3-nm-thick coating of phosphorylcholine covalently bound to the PED surface. ${ }^{20,24}$ It is thought that decreased protein adsorption and cell adhesion on surfaces with phosphorylcholine results in resistance to thrombogenesis. ${ }^{24}$ In vitro and ex vivo studies have supported this theory by demonstrating reduced thrombin generation and platelet deposition with PED-Shield compared with FDs without phosphorylcholine. ${ }^{17,20}$ Importantly, PED-Shield has also been effective clinically. Chiu et al. in 2016 used the PED-Shield to treat an intradural VA dissecting aneurysm. The patient underwent loading with $300 \mathrm{mg}$ aspirin before the procedure, received 1 dose of $20 \mathrm{mg}$ abciximab immediately after placement of the device, and then a heparin infusion for 5 days. Only aspirin was continued thereafter. Follow-up MRI at 2 weeks showed a small area of diffusion abnormality in the ipsilateral cerebellum, but another MRI session at 6 weeks showed no further evidence of thromboembolic events. ${ }^{8}$ In patients with ruptured aneurysms, the ability to use aspirin alone and the associated increased safety profile of aspirin alone compared to dual antiplatelet therapy offers a significant advantage over previous generations of flow-diversion technology.

\section{Conclusions}

Although blister aneurysm pathophysiology is not fully understood, the parent vessel wall fragility and the tendency to rupture intraoperatively have historically made this entity difficult to treat. Retrospective evidence suggests that blister aneurysms may be more amenable to en- dovascular treatment. Endovascular deconstructive treatment is not often possible and has unequivocal long-term ramifications, which make endovascular reconstructive treatment preferable. Use of flow-diversion technology is associated with a higher rate of mid- to long-term occlusion and a lower rate of retreatment compared with other endovascular treatment options, but FDs have not yet been found to have superior clinical outcomes. The technical difficulty of coiling and the lower rate of retreatment with flow diversion make it an attractive option, but this is tempered by the higher rate of thromboembolic events with FDs and the possibility for hemorrhagic complications with dual antiplatelet therapy. Finally, initiation of dual antiplatelet therapy in the context of flow diversion or stent placement does potentially complicate the treatment of patients with aneurysmal SAH from blister aneurysms, thus highlighting the importance of considering patients' needs for other procedures such as gastrostomy tube placement or ventriculoperitoneal shunting in this population. However, the advent of novel FDs with decreased thrombogenic properties, such as the PED-Shield, represents a key step forward and increases the potential for flow diversion becoming the gold standard for endovascular treatment of blister aneurysms.

\section{References}

1. Abe M, Tabuchi K, Yokoyama H, Uchino A: Blood blisterlike aneurysms of the internal carotid artery. J Neurosurg 89:419-424, 1998

2. Ashour R, Dodson S, Aziz-Sultan MA: Endovascular management of intracranial blister aneurysms: spectrum and limitations of contemporary techniques. J Neurointerv Surg 8:30-37, 2016

3. Aydin K, Arat A, Sencer S, Hakyemez B, Barburoglu M, Sencer A, et al: Treatment of ruptured blood blister-like aneurysms with flow diverter SILK stents. J Neurointerv Surg 7:202-209, 2015

4. Bulsara KR, Kuzmik GA, Hebert R, Cheung V, Matouk $\mathrm{CC}$, Jabbour P, et al: Stenting as monotherapy for uncoilable intracranial aneurysms. Neurosurgery 73 (1 Suppl Operative):ons80-ons85, 2013

5. Buyukkaya R, Kocaeli H, Yildirim N, Cebeci H, Erdoğan C, Hakyemez B: Treatment of complex intracranial aneurysms using flow-diverting Silk ${ }^{\circledR}$ stents. An analysis of 32 consecutive patients. Interv Neuroradiol 20:729-735, 2014

6. Causin F, Pascarella R, Pavesi G, Marasco R, Zambon G, Battaglia R, et al: Acute endovascular treatment ( $<48$ hours) of uncoilable ruptured aneurysms at non-branching sites using Silk flow-diverting devices. Interv Neuroradiol 17:357364, 2011

7. Chalouhi N, Zanaty M, Tjoumakaris S, Gonzalez LF, Hasan D, Kung D, et al: Treatment of blister-like aneurysms with the Pipeline Embolization Device. Neurosurgery 74:527532,2014

8. Chiu AHY, Ramesh R, Wenderoth J, Davies M, Cheung A: Use of aspirin as sole oral antiplatelet therapy in acute flow diversion for ruptured dissecting aneurysms. J Neurointerv Surg [epub ahead of print], 2016

9. Çinar C, Oran İ, Bozkaya H, Ozgiray E: Endovascular treatment of ruptured blister-like aneurysms with special reference to the flow-diverting strategy. Neuroradiology 55:441447, 2013

10. Consoli A, Nappini S, Renieri L, Limbucci N, Ricciardi F, Mangiafico S: Treatment of two blood blister-like aneurysms with flow diverter stenting. J Neurointerv Surg 4:e4, 2012 
11. Fang C, Tan HQ, Han HJ, Feng H, Xu JC, Yan S, et al: Endovascular isolation of intracranial blood blister-like aneurysms with Willis covered stent. J Neurointerv Surg [epub ahead of print], 2016

12. Fang YB, Li Q, Yang PF, Huang QH, Zhao WY, Xu Y, et al: Treatment of blood blister-like aneurysms of the internal carotid artery with stent-assisted coil embolization. Clin Neurol Neurosurg 115:920-925, 2013

13. Figueiredo EG, Foroni L, Monaco BA, Gomes MQT, Sterman Neto H, Teixeira MJ: The clip-wrap technique in the treatment of intracranial unclippable aneurysms. Arq Neuropsiquiatr 68:115-118, 2010

14. Fiorella D, Albuquerque FC, Deshmukh VR, Woo HH, Rasmussen PA, Masaryk TJ, et al: Endovascular reconstruction with the Neuroform stent as monotherapy for the treatment of uncoilable intradural pseudoaneurysms. Neurosurgery 59:291-300, 2006

15. Galal A, Bahrassa F, Dalfino JC, Boulos AS: Stent-assisted treatment of unruptured and ruptured intracranial aneurysms: clinical and angiographic outcome. Br J Neurosurg 27:607-616, 2013

16. Gaughen JR Jr, Hasan D, Dumont AS, Jensen ME, McKenzie J, Evans AJ: The efficacy of endovascular stenting in the treatment of supraclinoid internal carotid artery blister aneurysms using a stent-in-stent technique. AJNR Am J Neuroradiol 31:1132-1138, 2010

17. Girdhar G, Li J, Kostousov L, Wainwright J, Chandler WL: In-vitro thrombogenicity assessment of flow diversion and aneurysm bridging devices. J Thromb Thrombolysis 40:437-443, 2015

18. Gonzalez AM, Narata AP, Yilmaz H, Bijlenga P, Radovanovic I, Schaller K, et al: Blood blister-like aneurysms: single center experience and systematic literature review. Eur J Radiol 83:197-205, 2014

19. Grant RA, Quon JL, Bulsara KR: Oversized self-expanding stents as an alternative to flow-diverters for blister-like aneurysms. Neurol Res 36:351-355, 2014

20. Hagen MW, Girdhar G, Wainwright J, Hinds MT: Thrombogenicity of flow diverters in an ex vivo shunt model: effect of phosphorylcholine surface modification. J Neurointerv Surg [epub ahead of print], 2016

21. Hu YC, Chugh C, Mehta H, Stiefel MF: Early angiographic occlusion of ruptured blister aneurysms of the internal carotid artery using the Pipeline Embolization Device as a primary treatment option. J Neurointerv Surg 6:740-743, 2014

22. Ihn YK, Kim SH, Sung JH, Kim TG: The efficacy of endovascular treatment of ruptured blood blister-like aneurysms using stent-assisted coil embolization. Interv Neuroradiol 18:432-441, 2012

23. Ishikawa T, Nakamura N, Houkin K, Nomura M: Pathological consideration of a "blister-like" aneurysm at the superior wall of the internal carotid artery: case report. Neurosurgery 40:403-406, 1997

24. Iwasaki Y, Ishihara K: Phosphorylcholine-containing polymers for biomedical applications. Anal Bioanal Chem 381:534-546, 2005

25. Kalani MYS, Albuquerque FC, Levitt M, Nakaji P, Spetzler RF, McDougall C: Pipeline embolization for definitive endoluminal reconstruction of blister-type carotid aneurysms after clip wrapping. J Neurointerv Surg 8:495-500, 2016

26. Kubo Y, Ogasawara K, Tomitsuka N, Otawara Y, Watanabe M, Ogawa A: Wrap-clipping with polytetrafluoroethylene for ruptured blisterlike aneurysms of the internal carotid artery. Technical note. J Neurosurg 105:785-787, 2006

27. Kurokawa Y, Wanibuchi M, Ishiguro M, Inaba K: New method for obliterative treatment of an anterior wall aneurysm in the internal carotid artery: encircling silicone sheet clip procedure-technical case report. Neurosurgery 49:469-472, 2001
28. Lee BH, Kim BM, Park MS, Park SI, Chung EC, Suh SH, et al: Reconstructive endovascular treatment of ruptured blood blister-like aneurysms of the internal carotid artery. J Neurosurg 110:431-436, 2009

29. Li MH, Gao BL, Wang YL, Fang C, Li YD: Management of pseudoaneurysms in the intracranial segment of the internal carotid artery with covered stents specially designed for use in the intracranial vasculature: technical notes. Neuroradiology 48:841-846, 2006

30. Lin N, Brouillard AM, Keigher KM, Lopes DK, Binning MJ, Liebman KM, et al: Utilization of Pipeline Embolization Device for treatment of ruptured intracranial aneurysms: US multicenter experience. J Neurointerv Surg 7:808-815, 2015

31. Linfante I, Mayich M, Sonig A, Fujimoto J, Siddiqui A, Dabus G: Flow diversion with Pipeline Embolic Device as treatment of subarachnoid hemorrhage secondary to blister aneurysms: dual-center experience and review of the literature. J Neurointerv Surg 9:29-33, 2017

32. Malatesta E, Nuzzi NP, Divenuto I, Fossaceca R, Lombardi $M$, Cerini P, et al: Endovascular treatment of intracranial aneurysms with flow-diverter stents: preliminary single-centre experience. Radiol Med (Torino) 118:971-983, 2013

33. Mazur MD, Taussky P, MacDonald JD, Park MS: Rerupture of a blister aneurysm after treatment with a single flowdiverting stent. Neurosurgery 79:E634-E638, 2016

34. McLaughlin N, Laroche M, Bojanowski MW: Surgical management of blood blister-like aneurysms of the internal carotid artery. World Neurosurg 74:483-493, 2010

35. McTaggart RA, Santarelli JG, Marcellus ML, Steinberg GK, Dodd RL, Do HM, et al: Delayed retraction of the Pipeline Embolization Device and corking failure: pitfalls of Pipeline Embolization Device placement in the setting of a ruptured aneurysm. Neurosurgery 72 (2 Suppl Operative):E245E251, 2013

36. Meckel S, Singh TP, Undrén P, Ramgren B, Nilsson OG, Phatouros C, et al: Endovascular treatment using predominantly stent-assisted coil embolization and antiplatelet and anticoagulation management of ruptured blood blister-like aneurysms. AJNR Am J Neuroradiol 32:764-771, 2011

37. Meling TR, Sorteberg A, Bakke SJ, Sletteb $\varnothing$ H, Hernesniemi J, Sorteberg W: Blood blister-like aneurysms of the internal carotid artery trunk causing subarachnoid hemorrhage: treatment and outcome. J Neurosurg 108:662-671, 2008

38. Nakagawa F, Kobayashi S, Takemae T, Sugita K: Aneurysms protruding from the dorsal wall of the internal carotid artery. J Neurosurg 65:303-308, 1986

39. Nerva JD, Morton RP, Levitt MR, Osbun JW, Ferreira MJ, Ghodke BV, et al: Pipeline Embolization Device as primary treatment for blister aneurysms and iatrogenic pseudoaneurysms of the internal carotid artery. J Neurointerv Surg 7:210-216, 2015

40. Ogawa A, Suzuki M, Ogasawara K: Aneurysms at nonbranching sites in the surpaclinoid portion of the internal carotid artery: internal carotid artery trunk aneurysms. Neurosurgery 47:578-586, 2000

41. Ogawa M, Sakurai K, Kawaguchi T, Naiki-Ito A, Nakagawa M, Okita K, et al: Internal carotid artery blister-like aneurysm caused by Aspergillus-case report. Pol J Radiol 80:159-163, 2015

42. Ohara H, Sakamoto T, Suzuki J: Sclerotic cerebral aneurysms, in Suzuki J (ed): Cerebral Aneurysms. Tokyo: Neuron, 1979, pp 673-682

43. Patel BM, Ahmed A, Niemann D: Endovascular treatment of supraclinoid internal carotid artery aneurysms. Neurosurg Clin N Am 25:425-435, 2014

44. Peschillo S, Cannizzaro D, Caporlingua A, Missori P: A systematic review and meta-analysis of treatment and out- 
come of blister-like aneurysms. AJNR Am J Neuroradiol 37:856-861, 2016

45. Peschillo S, Miscusi M, Caporlingua A, Cannizzaro D, Santoro A, Delfini R, et al: Blister-like aneurysms in atypical locations: a single-center experience and comprehensive literature review. World Neurosurg 84:1070-1079, 2015

46. Peschillo S, Missori P, Piano M, Cannizzaro D, Guidetti G, Santoro A, et al: Blister-like aneurysms of middle cerebral artery: a multicenter retrospective review of diagnosis and treatment in three patients. Neurosurg Rev 38:197-203, 2015

47. Regelsberger J, Matschke J, Grzyska U, Ries T, Fiehler J, Köppen J, et al: Blister-like aneurysms-a diagnostic and therapeutic challenge. Neurosurg Rev 34:409-416, 2011

48. Rouchaud A, Brinjikji W, Cloft HJ, Kallmes DF: Endovascular treatment of ruptured blister-like aneurysms: A systematic review and meta-analysis with focus on deconstructive versus reconstructive and flow-diverter treatments. AJNR Am J Neuroradiol 36:2331-2339, 2015

49. Rouchaud A, Saleme S, Gory B, Ayoub D, Mounayer C: Endovascular exclusion of the anterior communicating artery with flow-diverter stents as an emergency treatment for blister-like intracranial aneurysms. A case report. Interv Neuroradiol 19:471-478, 2013

50. Sekula RF, Cohen DB, Quigley MR, Jannetta PJ: Primary treatment of a blister-like aneurysm with an encircling clip graft: technical case report. Neurosurgery 59 (1 Suppl 1):ONSE168, 2006

51. Sim SY, Chung J, Shin YS: Are blood blister-like aneurysms a specific type of dissection? A comparative study of blood blister-like aneurysms and ruptured Mizutani type 4 vertebral artery dissections. J Korean Neurosurg Soc 56:395399, 2014

52. Song J, Oh S, Kim MJ, Chung J, Lim YC, Kim BS, et al: Endovascular treatment of ruptured blood blister-like aneurysms with multiple ( $\geq 3$ ) overlapping Enterprise stents and coiling. Acta Neurochir (Wien) 158:803-809, 2016
53. Takahashi A: Surgical treatment of chimame (blood blister) like aneurysm at $\mathrm{C} 2$ portion of internal carotid artery. Surg Cereb Stroke 16:72-77, 1988

54. Tanoue S, Kiyosue H, Matsumoto S, Yamashita M, Nagatomi H, Mori H: Ruptured "blisterlike" aneurysm with a pseudoaneurysm formation requiring delayed intervention with endovascular coil embolization. Case report. J Neurosurg 101:159-162, 2004

55. Walsh KM, Moskowitz SI, Hui FK, Spiotta AM: Multiple overlapping stents as monotherapy in the treatment of 'blister' pseudoaneurysms arising from the supraclinoid internal carotid artery: a single institution series and review of the literature. J Neurointerv Surg 6:184-194, 2014

56. Yoon JW, Siddiqui AH, Dumont TM, Levy EI, Hopkins LN, Lanzino G, et al: Feasibility and safety of Pipeline Embolization Device in patients with ruptured carotid blister aneurysms. Neurosurgery 75:419-429, 2014

\section{Disclosures}

The authors report no conflict of interest concerning the materials or methods used in this study or the findings specified in this paper.

\section{Author Contributions}

Conception and design: Grandhi, Sy. Drafting the article: Peitz, Sy. Critically revising the article: all authors. Study supervision: Grandhi.

\section{Correspondence}

Ramesh Grandhi, Department of Neurosurgery, University of Texas Health San Antonio, 7703 Floyd Curl Dr., MC 7843, San Antonio, TX 78229. email: grandhi@uthscsa.edu. 